\title{
Financial Metrics In Wide-Moat Firms
}

\author{
David P. Boyd, (E-mail: d.boyd@neu.edu), Northeastern University \\ Robert C. Quinn, (E-mail: RQuinn@bostonprivatebank.com), Boston Private Bank
}

\begin{abstract}
According to Morningstar companies with certain structural characteristics enjoy economic moats. Compared to benchmark indices, Morningstar hypothesizes that over a ten-year time frame these firms will evidence superior price appreciation. Based on analysis of 1360 companies, this study supports the thesis of historical performance among wide-moat firms.
\end{abstract}

\section{INTRODUCTION}

$C$

$\mathrm{n}$ economic moat is a sustainable competitive advantage. Companies with a wide economic moat can repel competitors intent on raiding the market and contain those already present. A longtime champion of this concept, Warren Buffet scours for businesses that have "economic castles protected by unbreachable moats" (Morningstar, 2004, p. 10). Morningstar has also advanced this notion, arguing that such firms will generate superior shareholder value over the long-term (Larson, 2004). While such an assertion appears plausible, it has not been subjected to extensive empirical analysis. The purpose of this study is to gauge the longitudinal validity of Morningstar's claim. Specifically, do these structural characteristics represent advantages that lead to price appreciation?

\section{STRUCTURAL CHARACTERISTICS OF WIDE-MOAT FIRMS}

Morningstar (Sellers, 2003) has delineated four essential criteria that characterize wide-moat firms. In formulating its typology, Morningstar has drawn heavily on Michael Porter's (1980) precepts for competitive strategy.

\section{Economies Of Scale}

Some companies can build sustainable competitive advantage by scaling infrastructure. These firms can thrive as a low-cost provider even after their products have become commodities. With its direct sales of hardware, Dell Computer stands as a classic example. As the world's largest retailer with 5000 stores around the globe, Walmart can create similar pricing pressure for actual and potential competitors.

\section{High Customer-Switching Costs}

High barriers to entry deter encroachment. A firm can then cement its client base and induce customer "stickiness." Orthopedic surgeons, for example, prefer proprietary products with documented clinical histories. Aging but still active "baby boomers" assure a continuous patient base for doctors using the wares of Zimmer and Stryker.

\section{Intangible Assets}

Intellectual property protects firms from the clonal crowd. Patents afford protection whether the estate is cellphone chips or pharma product. For example, the bulk of Qualcomm's profits stem from patent royalties and CDMA chip sales. The company's net has surged an average of 92 percent over the past three years. Pfizer sells 14 of the world's top 25 medicines and seeks to maintain cash flow through authorized generics once those patents expire. Government permits can also bestow competitive benefit. A graying demographic will spur demand for Stericycle's medical waste services. Hospitals and clinics retain liability for waste even after it has been removed from their premises. Hence medical institutions gravitate toward providers whose treatment facilities have passed government 
muster. Another company with a distinctive government designation is Moody's. It claims the coveted certification of "nationally recognized statistical rating organization."

\section{Network Economics}

Trusted exchange mediums create a cascading conduit between buyers and sellers. Examples abound across sectors. AMEX credit cards project an ambiance of both exclusivity and efficiency. Software protocols such as Adobe's reader allow and augment communication. The free version of Acrobat has been downloaded 500 million times and is considered the de facto standard in document exchange. Morningstar sees eBay as the textbook example of the network effect. As this virtual community culls buyers and sellers, it becomes ever more enticing to prospective users.

\section{MOAT METRICS}

Appearing in Europe during the 1100s, large stone castles existed for nearly four centuries. Their purpose was to protect the realm for the king since a feudal lord was vassal to the king. A second function was to preserve the lord's own provincial power. Moats served as the first line in a castle's defense, reaching their apex in the thirteenth century. Behind the moat were more layered barriers, including a drawbridge, a gatehouse whose portcullis could be lowered, and a keep or great tower that stood as the final refuge during siege. This self-sufficient fortified tower functioned as the castle's main citadel. The round keep at Pembroke Castle, for example, measured 80 feet in height, contained four stories, and had walls 16 feet thick. When selecting stocks, Buffet prefers Great Danes to Chihuahuas (Schraeder, 2005b). If companies do not have a solid and substantive core business, they are "terminally ugly" (Mann, 2005, p. 10) and even a great manager cannot rescue them from their inherent shortcomings. Both Morningstar and Buffet would presumably warn investors to be wary of castles that seem splendid on the surface yet lack defenses to protect their pulchritude. Any success they enjoy will be ephemeral rather than enduring.

Although Morningstar does not pursue the implications of its historical analogy, presumably multiple moats would further fortify defenses. In gauging competitive strategy, analysts have observed that "where there is drift, there is risk" (Lehl \& Alexander, 2005). Multiple moat companies, however, can retain focus on core product even as they cater to diverse end markets. Such a company's clients might come from government as well as business. Deeply entrenched firms might also leverage core expertise through different but related products. Japanese castles often utilized multiple moats to deter and destroy invaders. This water model has an analogue in the wall formation of socalled concentric castles where the first wall was lower than the second. Castle defenders could aim weaponry at the advancing army without inflicting harm on fellow defenders stationed below.

In its search of the stock universe, Morningstar has accorded the wide-moat designation sparingly (Sellers, 2004). Only 154 large-caps qualify for such status. These companies resemble those castles whose moats could be as much as 30 feet deep and 12 feet wide. Some of those moats even contained submerged and sharpened wooden "bungy sticks" to impale attackers.

Morningstar has also produced a roster of 754 narrow moat companies. Endowed with a distinctive advantage, these companies provide shelter from the storm but by no means are they impregnable. In contrast, widemoat firms possess more than one of the four competitive advantages underpinning the Morningstar typology (Schrader, 2005a).

Most equities enjoy no real moat according to Morningstar. In historical terms these firms are reminiscent of those castles situated where water moats were impractical. Dry ditches were much more common than water-filled perimeters and so it is with equities today.

\section{STUDY HYPOTHESIS}

Morningstar avers that over time wide moat companies create economic value for shareholders (Figure 1). Since these companies will outperform, they should be buy and hold selections. If investors "avoid the flash" and stay 
the course, they will "find the cash" with Morningstar's list. The purpose of this study is to test Morningstar's assertion. A pilot survey last year lent some credence to the hypothesis (Boyd, 2005). The present study, however, examines the entire set of wide moat and narrow moat companies. It tracks longitudinal price appreciation and compares stock performance to the S\&P benchmark (SPX). Morningstar hypothesizes that after only five years, wide moat status will not be persistently and persuasively associated with price appreciation. Instead Morningstar advocates ten years as a minimal baseline, citing Stein's (Stein \& DeMuth, 2003) conclusion that value conscious investors require such a period of time to generate substantial excess returns. Accordingly, this study will examine the relationship of moat gradient to stock price at five- and ten-year intervals.

Figure 1: Economic Moats

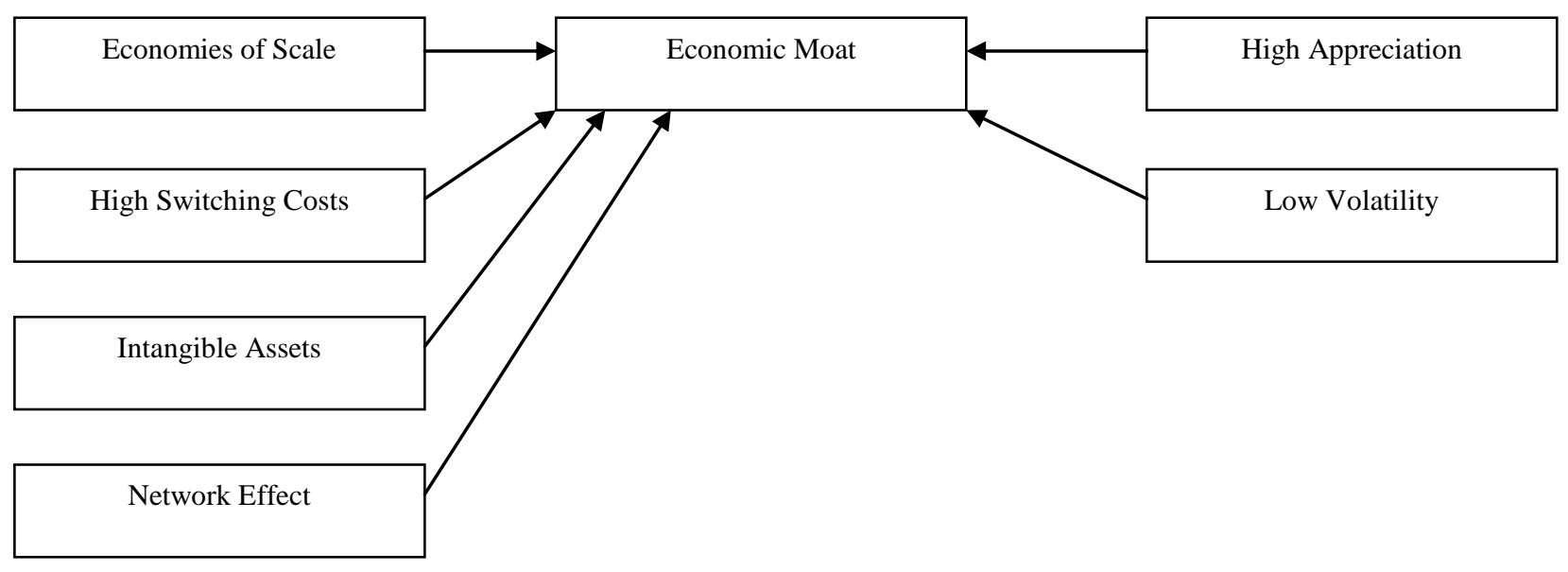

Inclusion on Morningstar's wide-moat roster is not tantamount to a buy recommendation. This elite cadre of large-caps and mid-caps is more akin to a watch list than a buy list (Larson, 2003). Morningstar advises purchase only at a discount to intrinsic value. At the present time few equities sport this kind of compelling valuation. Morningstar counsels patience, reminding investors that sooner or later many of these firms will temporarily hit a rough patch. Investors should wait for this "fat pitch" and be poised to swing when it comes (Sellers, 2004).

\section{DATA ANALYSIS}

The study utilizes three basic categories compiled by Morningstar. In addition to the 154 companies that enjoy wide-moat status and the 764 classified as narrow-moat, Morningstar's coverage set includes 659 companies that lack a moat. While by no means equivalent to the total universe of no-moat stocks, this group can serve as a proxy for the behavior of these supposedly suboptimal stocks. The composition of these various lists has remained relatively stable since inception (Larson, 2004). The prime endpoint of the study was to determine relative price appreciation of these moat and no-moat companies. Thomson Baseline provided and aggregated all data used in the study. This subscription-based diagnostic service has fundamental and pricing history on more than 9000 publicly traded U.S. equities. Even though Baseline is a comprehensive service, it excluded some Morningstar equities designated as American Depository Receipts. The Baseline analysis also deliberately omitted any Morningstar entries without at least a five-year history. Since the study design encompassed Morningstar's entire population, it could compute aggregate averages rather than extrapolate from significance tests of statistical samples. Findings are presented in Table 1.

\section{STUDY FINDINGS AND LIMITATIONS}

Results support Morningstar's thesis. Moat status is associated with higher returns for a ten-year period but not for a five. Moreover, in their price trajectory, moated firms demonstrate less volatility than their no moat cohort. 
The respective ten-year beta coefficients for the wide, narrow and no moat populations are 0.88, 0.90 and 1.19.

The study design suffers from limitations inherent in categorical analysis. While end points are continuous, moat classifications are dichotomous. Thus the study cannot determine whether appreciation would be progressively enhanced by position within the wide- and narrow-moat categories. Some companies may have wider moats than others even though they garner the same moat rating. Would these wider ones be better investments than their less wide peers? While the present analysis cannot address this issue conclusively, it provides suggestive evidence. Within the wide-moat category Morningstar identifies two subsets that it favors. The "Bellwether 50" is comprised of largecaps while another group consists of 35 mid-caps. The cumulative ten-year appreciation of the Bellwether roster was 509 percent compared to 451 percent for the entire wide-moat list. Among the subset of 35 mid-caps, the cumulative ten-year price appreciation was 488 percent. During this time the SPX rose 119 percent.

Table 1: Price Appreciation By Moat Category

\begin{tabular}{|c|c|c|c|c|}
\hline & 5 Year Change & $\begin{array}{c}\text { 5 Year Change } \\
\text { vs. SPX }\end{array}$ & 10 Year Change & $\begin{array}{c}\text { 10 Year Change } \\
\text { vs. SPX }\end{array}$ \\
\hline $\begin{array}{c}\text { Wide Moat } \\
\text { N = 144 }\end{array}$ & 57 & 75 & 451 & 332 \\
\hline $\begin{array}{c}\text { Narrow Moat } \\
\text { N =666 }\end{array}$ & 105 & 123 & 337 & 219 \\
\hline $\begin{array}{c}\text { No Moat } \\
\text { N =550 }\end{array}$ & 80 & 98 & 294 & 175 \\
\hline
\end{tabular}

Since Morningstar's rating system is retrospective, it could be subject to survivorship bias. A company may qualify for wide-moat status simply because it has done well in the past. As investors look to the future, they should remember that these wide moats can narrow over the very period of time when returns are expected to fructify. Though the ditch is unlikely to disappear, the water within may drain away. After all, the advent of gunpowder presaged the abolition of castles. Even with the Bellwether group, a perennial query must be "how nifty are these 50"? For example, take a closer look at some of the "textbook" wide-moats recurrently cited by Morningstar. Walmart is hailed as the low-cost gargantuan relentlessly advancing across product categories, epitomizing the first criterion of moat ascendancy. Morningstar argues that optimal leadership, while obviously desired, is not required in such firms because they are imbued with "structural advantages." Paraphrasing Peter Lynch, Morningstar declares that widemoat entities are so strong, even a monkey could be placed at the helm with no disruptive impact (Sellers, 2003). Yet in terms of investor relations, Walmart has been a recipe for disaster. Allegations of a discriminatory climate and a duplicitous director tarnish a reputation already sullied by union strife.

In terms of the second moat criterion pertaining to switching costs, even device makers are vulnerable to outside forces. Desirous of reining in their costs, hospitals aim to sever the cozy relationship between orthopedic surgeons and industry representatives. As an administrator noted, doctors will be more attracted to hospital incentives when they realize the implant representative in the operating room is making more than they are. As for intellectual property, can firms like Qualcomm assume their patents will be respected in other parts of the world? Some emerging markets may seek to institute their own variant of CDMA, making it difficult for Qualcomm to enforce its patents. Finally, in terms of network economics, success breeds imitation. A start-up firm is even hawking a cheaper PDF as an alternative to Adobe Acrobat. And while eBay is hardly tottering, Morningstar's classic example finds its trajectory threatened. Service complaints are rising, and competitors like Amazon are starting to strut. Ironically, technology enhancement may allow independent-minded entrepreneurs to bypass eBay and conduct Internet business on their own. Thus even if there is opportunity to buy Morningstar stocks at deeply discounted prices, investors must examine why the shares have retreated and ask whether these firms are now beset with a structural disadvantage.

The present study points to the historical efficacy of the Morningstar model. Yet Morningstar eschews endorsement of small firms and so invariably neglects the emergent secular themes to which some of these firms might play. While adherence to Morningstar's wide-moat classification may continue to generate above market 
returns, a modicum of "mad money" might nonetheless deserve a strategic place in individual portfolios. As this paper goes to press, Morningstar is stepping beyond the reliable record of its current lists. It is now vetting for a new category called "Emerging-Moat Growth Companies." This roster will include companies whose moats may one day be wide and whose competitive position may one day be "unassailable" (Trigg, 2005, p. 4). If Morningstar can forecast performance in emergent as well as established firms, its moat typology will be a valuable tool across the domestic spectrum.

\section{REFERENCES}

1. Boyd, David P., Financial Performance of Wide-Moat Companies, Journal of Business and Economics Research, Vol. 3, No. 2, pp. 49-56, 2005.

2. Larson, Paul, The Case for Wide-Moat Stocks, Morningstar.com, March 26, 2004.

3. Lehl, Brad and Alexander, James, Websense, Inc., Update, Jefferies and Company, Inc., p. 1, June 29, 2005.

4. $\quad$ Mann, Bill, Interview: Philip Tasho, Motley Fool Hidden Gems, Vol. 3, No. 7, pp. 1-10, 2005.

5. Morningstar, StockInvestor Reader's Guide, Morningstar, Inc., Chicago, Illinois, 2004.

6. $\quad$ Porter, Michael, Competitive Strategy, Free Press, New York, New York, 1980.

7. Schrader, Jonathan, An Inside Look at How We Assign Economic Moats, Morningstar StockInvestor, Vol. 4, No. 10, April 15, 2005a.

8. , The Wisdom of Buffet and Munger, Morningstar StockInvestor, Vol. 4, No. 12, June 15, $2005 b$.

9. Sellers, Mark A., The Four Principles of Profitable Investing, Morningstar, Inc., Chicago, Illinois, 2003.

10. _ The Fat-Pitch Approach to Stock Investing, Morningstar.com, January 28, 2004.

11. Stein, Ben and DeMuth, Phil, Yes, You Can Time the Market, John Wiley, New York, New York, 2003.

12. Trigg, Mike, How to Profit from Growth Stocks with Less Risk, Introducing Morningstar GrowthInvestor, pp. 1-6, June 2005. 


\section{NOTES}

